\section{COLUMN: EDITOR'S NOTES}

\section{January 2020}

\section{Charles B. Hodges ${ }^{1}$}

Published online: 5 December 2019

(C) Association for Educational Communications \& Technology 2019

Welcome to a new volume year for TechTrends! There are three special issues planned for this year. You can look forward to special issues later this year focusing on Organizational Training and Performance, Authentic Learning in Distance Education, and Systems Thinking and Change. The current issue of the journal is a regular issue consisting of papers on a number of topics and some of our regular columns.

The papers in this issue begin with a collection of three papers on topics in Computational Thinking. First, Hunsaker and West have provided a design case on a project to design computational thinking and coding badges for early childhood educators. That is followed by Zha, Jin, Moore, and Gaston's description of their work using Hopscotch in a Computational Thinking module for pre-service K-8 teachers. Then, Caeli and Yadav examine the historical route of computational thinking and how history can inspire and inform initiatives today in an historical perspective to unplugged approaches to Computational Thinking, which is the last Computational Thinking paper in this issue. Jones, Cohen, Schad, Caratachea, and Smith share their work with professional development for $\mathrm{K}-12$ teachers in a commercial makerspace. Transitioning from makerspace oriented topics we have an eclectic mix of four papers. First, Steven Baule reports on his work analyzing special education cooperative websites to determine their accessibility for individuals with disabilities. A review of the research on how social media have been integrated in high school writing instruction is provided by Sarah Galvin and Christine Greenhow. Blended learning in middle schools at a public charter school system is the topic of the next paper by Fazzal, Panzano, and Luk, which is followed by an exploration of career decisionmaking among Instructional Design students by Mills, Stefaniak, Luo, and Glass. The remaining seven papers in the issue generally fall into the theme of teaching and learning in higher education. First, Hromalik, Myhill, and Carr report on

Charles B. Hodges

chodges@georgiasouthern.edu

1 Georgia Southern University, Statesboro, GA, USA their work to design and develop the Universal Design for Learning (UDL) Academy which was designed to guide community college faculty in applying the UDL framework to their instruction. M. David Merrill shares his syllabus review checklist that is used to promote problem-centered instruction. Next, Bilgin and Gul describe their investigation of the effect of gamification on the attitudes of students towards group learning environments, their course, group cohesion, and their academic achievement. Their work on the motivational effects of involving students in rubric development is described by Zheng, Ding, $\mathrm{Lu}$, and Branch. Then, Farmer, Catalano, and Halpern explain their research on student preference between textbook chapters and adaptive learning lessons in an introductory environmental geology course. Moving to face-to-face classrooms for one paper, Zheng, Watson, Watson, and Janakiraman explore how to provide effective attitudinal learning in large-enrollment classrooms. Finally, Choo, Bakir, Scagnoli, Ju, and Tong share their results utilizing the community of inquiry framework to understand students' learning experience in online undergraduate business courses.

The columns in this issue include a description of mentoring doctoral students in China in ICT International, the experiences of a graduate student working on the development of an educational game in Graduate Member Musings, Part II of A HighLevel Overview of Virtual Leadership According to Educational Technology Scholars in Leading Matters, and a review of the book, $3 D$ Printing: An Introduction, in Book Reviews. I hope you enjoy all that this issue has to offer!

As always, if you are interested in submitting a manuscript to TechTrends, or if you want to be a reviewer, please contact me. Encourage your colleagues to submit their work to TechTrends, to read TechTrends, and to consider joining AECT! If you have a question about the journal, my phone number is 912-478-0497 and my email address is chodges@georgiasouthern.edu. Email is always the best way to reach me. Also, you can follow TechTrends on Twitter: @AECTTechTrends.

Publisher's Note Springer Nature remains neutral with regard to jurisdictional claims in published maps and institutional affiliations. 